\title{
Attenuation in autoshaped responding produced by US reactivation treatment following extinction
}

\author{
STEVE REILLY and TODD R. SCHACHTMAN \\ University of York, York, England \\ (Ralph R. Miller, Sponsor)
}

\begin{abstract}
Two experiments examined the effects of US priming/reinstatement treatments on pigeons' responding to a partially extinguished CS. In Experiment 1, the subjects were given autoshaping to a keylight paired with food, and then responding to the keylight was partially extinguished. The subjects were subsequently given four presentations of food, that is, US priming/reinstatement treatment, approximately 30 min prior to testing with the CS. In contrast to previous reports that have demonstrated a reinstatement-induced facilitation of performance in rats, the present results yielded an attenuation in conditioned responding following the US reinstatement treatment relative to responding by a control group that did not receive the reinstatement presentations. In Experiment 2 we sought to distinguish between a priming account and some of the alternative interpretations of the results of Experiment 1 . The subjects were given autoshaping with two separately trained keylights, and then responding to the target CS was partially extinguished. Consistent with a priming interpretation of the previous finding, nonreinforced presentations of the nonextinguished keylight approximately $30 \mathrm{~min}$ prior to testing with the extinguished CS attenuated conditioned responding.
\end{abstract}

Presentations of the unconditioned stimulus (US) following extinction of a CS-US association and prior to testing the conditioned stimulus (CS) have been shown to facilitate conditioned responding in such preparations as conditioned suppression (e.g., Bouton \& Bolles, 1979; Rescorla, 1973) and conditioned taste aversion (Schachtman, Brown, \& Miller, 1985). This procedure is often referred to as the US reinstatement procedure.

Regardless of the theoretical account one adopts for the US reinstatement effects (see, e.g., Bouton \& Bolles, 1979; Rescorla, 1973, 1974; Schachtman et al., 1985), it is noteworthy that little work has been reported that concerns reinstatement of an extinguished CS-US autoshaped association using pigeons. This is surprising considering the frequent use of pigeons in classical conditioning studies and the import attributed to the autoshaping procedure. The initial aim of the present research was to examine the effects of US reinstatement on appetitive associations in pigeons.

This research was supported by a Medical Research Council grant to Euan Macphail. We thank Mark Good, Wes Kasprow, Ralph Miller, and Phil Reed for their comments on an earlier version of this manuscript. Correspondence should be addressed to either S. Reilly, Department of Psychology, Memorial University of Newfoundland, St. Johns's, NF A1B 3X9, Canada, or T. R. Schachtman, Division of Behavioral and Psychosocial Medicine, Department of Psychiatry, University of Rochester Medical Center, Rochester, NY 14642.

\section{EXPERIMENT 1}

In Experiment 1, the pigeons were given autoshaping training and then extinction. The next day, the subjects were given presentations of the US $30 \mathrm{~min}$ prior to testing. These US reinstatement presentations may increase the associative strength of the conditioning context and enhance performance through summation of the contextUS and CS-US associations (Bouton \& Bolles, 1979). Since this effect may obscure the potential for observing a reinstatement effect due to other mechanisms, an attempt was made to limit the influence of associative summation by administering the reinstatement presentations in a radically dissimilar context from that used for training and testing.

\section{Method}

Subjects. The subjects were 12 adult pigeons (Columba livia) maintained at $80 \%$ of their ad-lib feeding weights. All birds had previously served in an autoshaping experiment, but they were naive with respect to the present stimuli.

Apparatus. Two distinctive enclosures were used in the present experiment. The context used for conditioning and testing was a standard, nonilluminated pigeon chamber (for details, see Hall, Channell, \& Schachtman, 1987). The center key could be illuminated from behind with blue light.

The reinstatement chamber was similar to that used by Rudolph and Van Houten (1977) and the walls were lined with 2-mm yellow and green vertical stripes. The chamber had a red houselight and a continuously presented 16-dBA re: SPL tone above a 62-dBA background sound level. 
On the front wall of the chamber, there was a recess $(9 \times 9 \times 6 \mathrm{~cm})$ in which a grain feeder was located $8 \mathrm{~cm}$ above the floor level. An infrared photocell detected hopper entries when the food magazine was operated.

Procedure. Because of their previous experience with autoshaping, the subjects required no pretraining. On the first 6 days of the experiment, the subjects received $305-\mathrm{sec}$ presentations of a blue keylight, each followed by $5 \mathrm{sec}$ access to the grain hopper. These trials were scheduled on a VT 60-sec intertrial interval (ITI).

On the next day, responding to the blue keylight was extingished. Extinction trials were given until each bird met a criterion of five consecutive trials without a response to the key. The subjects received treatment identical to that during conditioning, except that the food presentations were omitted and the session was terminated following the completion of the extinction criterion. Following extinction, the subjects were assigned to one of two groups $(n s=6)$, Group Control and Group US, counterbalanced for the number of trials taken to complete the extinction criterion.

On the next day, each subject was placed in the reinstatement chamber. Each subject in Group US received four presentations of the food hopper, whereas those in Group Control received none. The first presentation for Group US occurred $3 \mathrm{~min}$ into the session. The remaining three food presentations were delivered 2 min following the preceding one. A 2-min interval occurred between the final food presentation and the removal of the subjects from the chamber. All food presentations remained available for $10 \mathrm{sec}$ following the initiation of eating from the hopper. At the end of the reinstatement session, all subjects were replaced in the home cage for $30 \mathrm{~min}$. The birds were then put in the training/test chamber, and they received a single session of testing in extinction on the blue keylight CS. This session was identical to that of the previous extinction session except that it continued for 48 trials.

\section{Results and Discussion}

All subjects acquired keypecking during the 6 days of autoshaping. On Day 6 of training, the birds that were to become Group Control and Group US yielded similar group means of 27.2 and 25.3 trials with a response, respectively, of the 30 trials in the session $(F<1)$. During extinction, Groups Control and US required comparable means of 35.8 and 29.0 trials, respectively, until the criterion was satisfied $(F<1)$. On the test day, the mean number of trials with a response was 21.0 for Group Control, which indicates that only partial extinction of the CS-US association had occurred. However, Group US yielded a significantly lower mean of 10.7 trials with response $[F(1,10)=13.97, p<.01]$. These results indicate that, rather than producing a reinstatement-induced enhancement of responding, US reinstatement presentations following extinction and prior to testing caused an attenuation in responding relative to responding of a control group given no US presentations in the reinstatement chamber.

\section{EXPERIMENT 2}

The findings of Experiment 1 might have been due to the food presentations producing a short-term satiation effect that attenuated subsequent performance. Alternatively, these presentations might have resulted in a priming of the US representation and a consequent attenuation of performance at the time of testing (Wagner, 1976, 1978). Wagner stated that a US presentation causes "self- generated priming" of the US representation into active memory. If the US representation has already been primed into active memory, then responding to a CS that is associated with that US is attenuated, as is learning if subjects receive a CS paired with the US while the primed US representation remains in active memory. In Experiment 1, recovery of responding by Group Control presumably occurred because of the residual CS-US association remaining after extinction. For Group US, the reinstatement presentations of food might have primed the US representation into active memory and served to attenuate performance.

If self-generated priming of the US representation was responsible for the results of Experiment 1, then priming the US representation through "retrieval-generated priming"' should also produce a diminution in conditioned responding (see Wagner, 1976, 1978). In Experiment 2, subjects were given autoshaping with two keylights, each separately paired with reinforcement. Then one CS was extinguished as in Experiment 1. Prior to testing, half the subjects were given presentations of the nonextinguished keylight in the absence of food. These presentations may prime the US representation into active memory through retrieval-generated processing. If priming was the process responsible for the results of Experiment 1, then this treatment should produce lower test-trial responding by subjects that receive the presentations of the nonextinguished CS than by subjects that do not. A satiation interpretation of the results of Experiment 1 cannot address a response decrement produced by nonreinforced CS presentations. Because the present reinstatement treatment was not likely to result in substantial context-US associations, the reinstatement treatment occurred in the same context as that in which the subjects were trained and tested in the present experiment.

\section{Method}

Subjects and Apparatus. Ten pigeons served as subjects and were maintained similarly to those in Experiment 1 . The birds had previously served in an autoshaping experiment, but they were naive with respect to the stimuli employed in this study.

The birds were trained in one of four identical, nonilluminated pigeon chambers (for details, see Reilly \& Schachtman, 1987). The center key could be illuminated from behind with an orange light (Stimulus O) or a white diamond on a dark background (Stimulus D). An infrared photocell detected hopper entries when the food magazine was operated.

Procedure. Because the pigeons had previously served in an autoshaping study, no pretraining was necessary. Conditioning and the extinction sessions were identical to those of Experiment 1 except that the subjects were trained with two CSs. Briefly, the subjects received 30 pairings of each of the two keylights (Stimuli O and D) with food in a pseudorandom order on each of 8 days. A VT 30-sec ITI occurred between each keylight-food pairing. One bird failed to keypeck to either stimulus and was excluded from the study. After autoshaping training, responding to Stimulus $\mathrm{O}$ was extinguished to a criterion of five consecutive trials without a response.

On the day following the extinction session, the birds were assigned to one of two groups, Group Control $(n=4)$ or Group CS $(n=5)$, counterbalanced for the number of trials taken to complete the extinction criterion. The subjects in Group CS were placed in the training context and received four 5-sec presentations of Stimulus D. Subjects in Group 
Control were given the same treatment as Group CS, except that Stimulus $\mathrm{D}$ was not presented. Following completion of this session, the birds were replaced in the home cage for $30 \mathrm{~min}$ as in Experiment 1. After this period, the birds were returned to the chamber and received a single session of testing in extinction on Stimulus $\mathrm{O}$ for $\mathbf{4 8}$ trials. All remaining details of the experiment were the same as in Experiment 1.

\section{Results and Discussion}

Except for the 1 bird already noted, all subjects acquired keypecking to both CSs during the 8 days of autoshaping. On Day 8 of training, the birds that were to become Group Control and Group CS yielded identical group means of 27 trials (out of 30 ) with a response $(F<1)$. During extinction, Group Control and Group CS yielded means of 18.3 and 18.6 trials, respectively, to complete criterion $(F<1)$. On the test day, the mean number of trials with a response was 9.3 and 4.0 for Group Control and Group CS, respectively $[F(1,7)=4.26, p<.05$, one-tailed test].

This experiment yielded an attenuation in responding when subjects were given CS presentations shortly prior to testing. According to priming theory (Wagner, 1976, 1978), the CS presentation should have reactivated the US representation and caused this representation to be present in active memory during the CS test trials. These results lend support to a priming account of the US reinstatement-induced attenuation in conditioned responding obtained in Experiment 1, although this conclusion must be viewed as tentative because the reinstatement treatment occurred in different contexts for the experiments. Moreover, the results of Experiment 2 may have been produced by stimulus generalization between the keylights.
The source of the discrepancy between the present effects of reinstatement-produced attenuation in performance and previous demonstrations of an enhancement in responding is not immediately clear. A number of factors, including the species, autoshaping procedure, and the short reinstatement-test interval used in the present study, merit consideration.

\section{REFERENCES}

Bouton, M. E., \& Bolles, R. C. (1979). Role of conditioned contextual stimuli in reinstatement of extinguished fear. Journal of Experimental Psychology: Animal Behavior Processes, 5, 363-378.

Hall, G., Channell, S., \& Schachtman, T. R. (1987). The instrumental overshadowing effect in pigeons: The role of response bursts. Quarterly Journal of Experimental Psychology, 39B, 173-188.

Reilly, S., \& Schachtman, T. R. (1987). The effects of ITI-fillers in autoshaping. Learning \& Motivation, 18, 202-219.

ResCoRLA, R. A. (1973). Effect of US habituation following conditioning. Journal of Comparative \& Physiological Psychology, 82, 137-143.

REsCorla, R. A. (1974). Effect of inflation of the unconditioned stimulus value following conditioning. Journal of Comparative \& Physiological Psychology, 86, 101-106.

RudolPh, R. L., \& VAN Houten, R. (1977). Auditory stimulus control in pigeons: Jenkins and Harrison (1960) revisited. Journal of the Experimental Analysis of Behavior, 27, 327-330.

Schachtman, T. R., Brown, A. M., \& Miller, R. R. (1985). Reinstatement-induced recovery of a taste- $\mathrm{LiCl}$ association following extinction. Animal Learning \& Behavior, 13, 223-227.

W AGNer, A. R. (1976). Priming in STM: An information-processing mechanism for self-generated or retrieval-generated depression in performance. In T. J. Tighe \& R. N. Leaton (Eds.), Habituation: Perspectives from child development, animal behavior and neurophysiology (pp. 95-128). Hillsdale, NJ: Erlbaum.

WAGNER, A. R. (1978). Expectancies and the priming of STM. In S. H. Hulse, H. Fowler, \& W. K. Honig (Eds.), Cognitive processes in animal behavior (pp. 177-209). Hillsdale, NJ: Erlbaum. 